\title{
Proposta de modelo estatístico para hierarquização do resultado de pesquisas de satisfação de clientes
}

\author{
Statistical model proposal for ranking the results of \\ customer satisfaction surveys
}

\section{Raísse Layane de Paula Saraiva \\ José de Paula Barros Neto \\ Luiz Maurício Furtado Maués}

\section{Resumo}

A tender aos requisitos dos clientes é primordial para qualquer empresa ou indústria, uma vez que entregar aos clientes o produto que eles desejam é a sua razão de existir. Nos projetos habitacionais, compreender e traduzir tais requisitos em atributos de projeto visa buscar a total satisfação dos clientes e garantir vantagem competitiva. Para tanto, metodologias baseadas em aspectos qualitativos vêm sendo desenvolvidas, ainda assim, estas apresentam limitações quanto à garantia da qualidade dos produtos imobiliários. Com o intuito de propor um modelo para hierarquizar requisitos resultados de pesquisas de satisfação, baseado em aspectos quantitativos, este trabalho se dispôs a analisar um banco de dados composto por pesquisas de satisfação de empreendimentos habitacionais de padrões econômicos distintos. Foram empregadas análises das medidas de tendência central e dispersão, determinação da confiabilidade por meio do Alpha de Cronbach e análise fatorial. Pôde-se constatar que a principal ferramenta capaz de atender aos objetivos é a análise fatorial, sendo os aspectos construtivos com maior possibilidade de fornecer satisfação aos clientes aqueles relacionados a tamanho, qualidade, funcionalidade e conforto.

Palavras-chave: Satisfação. Requisitos de clientes. Produtos imobiliários. Modelo estatístico.

\begin{abstract}
Meeting customer requirements is crucial for any company or industry, since delivering to customers the products they need or desire is their reason for existing. In housing projects, understanding those requirements and translating them into design attributes is a way to achieve customer satisfaction and ensure a competitive edge to the company. In order to do that, different methods focused on the qualitative aspects have been used. However, those methods have proven to be limited with regards to ensuring the quality of building products. With the purpose of proposing a method to build a hierarchy of the requisites resulting from customer satisfaction surveys, based on quantitative aspects, this study analysed a databank formed by customer satisfaction surveys in housing developments with different economic standards. The study applied measures of central tendency and dispersion, reliability tests by means of the Cronbach's Alpha and factor analysis. The results show that the main tool to help meeting the aims is factor analysis, with the constructive aspects related to size, quality, functionality and comfort more likely to provide satisfaction to customers.
\end{abstract}

Keywords: Satifafaction. Customer requirements. Real estate products. Statistical model. 


\section{Introdução}

A satisfação dos clientes vem sendo estudada há algum tempo, desde quando garantí-la tornou-se o objetivo de destaque das organizações (KAPLAN; NORTON, 1992). Todavia, tal satisfação só pode ser alcançada em sua completude quando se consegue compreender as expectativas dos clientes (KAMARA; ANUMBA; EVBUOMWAN, 1999), o que difundidas correntes de pensamento em gestão denominam de valor e sua especificação se constitui um grande desafio (KOSKELA, 2000). Mais recentemente, Hatoum et al. (2018) afirmaram que a satisfação do usuário final é um dos principais índices que afetam o sucesso do projeto, em termos de agregar valor para o cliente. Milion, Alves e Paliari (2016) cruzaram informações de bancos de dados de reclamações e pesquisas de satisfação dos clientes e puderam constatar que alguns clientes poderiam estar insatisfeitos quanto à qualidade da construção e ainda assim satisfeitos quanto ao projeto em geral, o que revela que a satisfação geral ainda é uma variável complexa.

Ao mesmo tempo, a busca por uma definição para valor motivou a análise de dezenove anos de publicações do International Group for Lean Construction (IGLC), realizada por Salvatierra-Garrido, Pasquire e Miron (2012), concluindo que o conceito foi amplamente influenciado pelo modelo transformação-fluxo-valor (TFV), de Koskela (2000), que ainda possui ambiguidades em sua definição, e que o objetivo principal é atender aos requisitos dos clientes. No setor habitacional brasileiro, destacam-se pesquisas recentes voltadas ao entendimento da formação de valor pelos seus usuários finais (MONTEIRO; MIRON, 2018, 2016; MONTEIRO et al., 2015; BRITO; FORMOSO, 2014; BRITO; FORMOSO; ROCHA, 2012; BONATTO, 2010). No cenário internacional, Dlouhy e Haghsheno (2018) afimaram que o valor para o cliente é o principal conceito do Lean Thinking, não sendo dada a atenção necessária a este conceito na construção, uma vez que ainda existem inconsistências no seu entendimento. Drevland e Tillman (2018) ressaltam que no processo construtivo há inúmeros clientes envolvidos e, segundo a ótica da Lean Construction, todos esses clientes deveriam ser satisfeitos ao longo do processo, o que pode motivar uma ampla discussão. Giménez et al. (2019) desenvolveram um modelo de análise de valor com base em Design Science Research e no Kano model, criando três índices de valor: desejado, potencial e gerado.

Segundo Sampaio et al. (2011), a utilização de informações advindas dos clientes em novos projetos, ainda se dá de forma incipiente. Tal processo vem sendo denominado de retroalimentação, e tal situação pode ser comprovada através de simples busca por dissertações e teses na Biblioteca Digital Brasileira de Teses e Dissertações (BDTD) que contenham os termos "retroalimentação" e "projetos" simultaneamente em seu título e que tenham sido desenvolvidos nos últimos 10 anos, citando os trabalhos de Sampaio (2010) e Carneiro (2013). Para aprofundar o problema, ainda que mesmo conhecendo os requisitos dos clientes, administrá-los e interpretá-los é uma ação que requer vasta experiência na área e, ainda assim, não garante que os anseios dos mesmos sejam alcançados (LINDAHL; RYD, 2007). Kärna e Junnonen (2005) afirmam que, na construção civil, o principal objetivo da retroalimentação tem sido verificar a satisfação dos clientes, ou seja, é deixado de lado o potencial de utilização destas informações para o desenvolvimento de novos produtos com base nas experiências advindas de outros já entregues, sendo priorizada a mensuração da satisfação. Sampaio (2010) ressalta que, mesmo que as necessidades e valores sejam diferentes entre as pessoas, é necessário utilizar dados coletados em avaliações de satisfações no desenvolvimento de novos projetos, a fim de buscar um maior grau de satisfação dos clientes finais.

Para desenvolver produtos com o valor buscado pelos clientes diversas metodologias de mensuração da satisfação de clientes, bem como da viabilização do emprego destas pesquisas em novos projetos vêm sendo criadas e desenvolvidas. Destacam-se o Client Requirement Processing (CRP), o Briefing (KAMARA; ANUMBA; HOBBS, 1999) e o Quality Function Deployment (QFD) (DELGADO-HERNANDEZ; BAMPTON; ASPINWALL, 2010). O Kano Model (JYLHA; JUNILLA, 2012) e modelo teórico desenvolvido por Sampaio (2011). Tais metodologias podem ter ainda dois objetivos principais, isto é, podem apenas levantar o nível de satisfação dos clientes ou podem ser responsáveis por transformar requisitos de clientes em requisitos de projeto.

Apesar da existência dos modelos citados, a sua utilização ainda é limitada na bibliografia, desta forma, este trabalho tem por objetivo agregar mais uma possibilidade na hierarquização dos resultados de pesquisas de avaliação e propõe um modelo quantitativo para esta finalidade. 


\section{Referencial teórico}

Ainda que existam diversos tipos de clientes, sabe-se que todos possuem aspirações e exigências para os produtos ou bens que adquirem, tais aspirações são definidas por Sandroni (1998) como as necessidades, aquilo que precisa ser atendido para viabilizar o alcance da satisfação.

De forma concisa, Miron, Echeveste e Formoso (2008) estabelecem que requisitos se referem a necessidades e expectativas com relação a um determinado produto ou serviço, por parte dos clientes ou outro grupo de clientes. Especificamente quando o produto é um empreendimento imobiliário, os requisitos dizem respeito às funções a serem realizadas por ele, tais quais: morar, trabalhar, descansar, estudar (MIRON; FORMOSO, 2002). Nesse contexto, a definição de satisfação é de extrema importância, tal como citado por Woodruff (1997), diz respeito ao sentimento do cliente em resposta à avaliação de experiências de uso com o produto. Mais recentemente, Lima (2011) cita que a satisfação está associada à confirmação ou desconfirmação das expectativas do cliente. Em suma, a satisfação está relacionada ao atendimento dos requisitos ou expectativas dos clientes, principalmente aqueles que compreendem valor em sua experiência de uso ou consumo.

Visando a garantir que essas expectativas sejam atendidas, o processo de retroalimentação na construção civil visa desenvolver novos empreendimentos mais adequados às suas necessidades. Este é um campo que vem avançando com o estudo do ambiente construído, fato que pode ser comprovado com métodos mais recentes que se baseiam em Building Information Modelling (BIM), como em Fernandes, Formoso e Tzortzopoulos-Fazenda (2018), cujo objetivo era propor um método automatizado de verificação de requisitos para empreendimentos de habitação de interesse social (HIS) e Baldauf, Miron e Formoso (2013) que propuseram um método para modelar requisitos de clientes com suporte do BIM. Ainda acerca da retroalimentação, cita-se o trabalho de Aragão e Hirota (2016) que objetivou a estruturação e organização dos requisitos dos usuários como dados de entrada no processo de projeto de HIS.

O Grupo de pesquisa e Assessoria em Gerenciamento da Construção Civil (GERCON) desenvolveu inúmeras pesquisas de satisfação de clientes desde a fundação em 2000. Todavia, somente as informações qualitativas advindas das pesquisas foram utilizadas, mesmo sendo gerados diversos resultados numéricos, não explorados até então. Buscou-se então construir um modelo de análise quantitativa de pesquisas de satisfação, que pudesse contribuir de algum modo com a retroalimentação do processo de projeto. Para possibilitar este desenvolvimento, foram estudadas métricas e ferramentas estatísticas, a fim de determinar aquelas com maior possibilidade de contribuir para o alcance do objetivo do trabalho.

De acordo Triola (2012), as medidas de tendência central, ou medidas de centro, são valores que resumem informações acerca de um conjunto de dados. De acordo com Fávero et al. (2009), as medidas de tendência central não são capazes de avaliar a variabilidade de um conjunto de dados ou observações. Daí, surge a necessidade de, além de calcular os indicadores de tendência central de determinada variável, faz-se necessário conhecer também sua variabilidade, ou dispersão.

Segundo Cortina (1993), o coeficiente Alpha de Cronbach foi descrito em 1951 por Lee J. Cronbach (CRONBACH, 1951) e é um indicador utilizado para medir a confiabilidade do tipo consistência interna de uma escala, isto é, para avaliar a magnitude em que os itens de um instrumento estão correlacionados. Streiner (2003) estabelece que o resultado mínimo aceitável deste indicador é de 0,70, uma vez que se obtenha resultados abaixo deste, a consistência interna da escala é considerada baixa. Já Hair Junior et al. (2005), estabelece que o valor mínimo aceitável é de 0,6 , sendo o resultado 0,7 já considerado satisfatório. Haja vista a limitada aplicação do coeficiente para trabalhos similares e, portanto, a falta de parâmetros, este trabalho adotará o valor de 0,6 como resultado mínimo aceitável.

Segundo Reis (2001) a análise fatorial (AF) inclui algumas técnicas estatísticas no qual o seu objetivo é representar um número real de variáveis a partir de um menor número de variáveis hipotéticas, denominadas fatores, obtidos de combinações lineares das variáveis originais.

\section{Método}

Para o desenvolvimento deste trabalho foram utilizadas pesquisas de satisfação realizadas entre os anos de 2014 e 2015 por Morais (2015), logo, serão utilizados no trabalho em questão dados secundários. Estas pesquisas foram desenvolvidas em empreendimentos do Programa Minha Casa Minha Vida (MCMV), compreendendo 362 questionários aplicados, em 10 municípios cearenses diferentes, incluindo a capital do estado; e em empreendimentos de médio e alto padrão com 138 questionários aplicados desenvolvidos para 
construtoras cearenses, em três empreendimentos executados por três empresas distintas, totalizando 500 questionários.

Os dois questionários utilizados nas pesquisas supracitadas tiveram características distintas, conforme é apresentado no Quadro 1. O questionário aplicado aos empreendimentos de médio e alto padrão possuía ainda 2 grupos de resposta: satisfação e importância, todavia, a fim de uniformizar as análises, somente as respostas para "satisfação" foram levadas em consideração, uma vez que o questionário aplicado às obras do programa MCMV só continham esta informação como resposta.

A revisão bibliográfica possibilitou a definição das medidas ou ferramentas de análises a serem empregadas, escolhendo aquelas que possivelmente retornariam resultados relevantes do ponto de vista dos objetivos do trabalho. Deste modo, a Figura 1 busca ilustrar o modelo de análise proposto e a sucessão das etapas ao longo deste trabalho. Ressalta-se que, apesar do uso já difundido de algumas destas medidas ou ferramentas, a inovação desse trabalho diz respeito à utilização destas medidas como um modelo composto, sendo obtidas informações em cada fase para propiciar a retroalimentação.

Inicialmente as pesquisas foram organizadas e sistematizadas em bancos de dados. Foi então realizada uma pesquisa bibliográfica a fim de buscar ferramentas estatísticas que apontassem como propícias à utilização e alcance do objetivo do trabalho. O Alpha de Cronbach tem o objetivo de determinar a consistência interna de uma escala, sendo o primeiro indicador utilizado para aferir a confiabilidade dos dados em análise. Posteriormente, uma análise descritiva foi realizada, a fim de determinar parâmetros estatísticos básicos, tais como média e mediana. Depois foram determinadas as medidas de dispersão (variância, desvio padrão e coeficiente de variação), a fim de analisar a variabilidade dos dados. Posteriormente, a análise fatorial objetivou determinar quais variáveis eram responsáveis por impactar mais ou menos a variável "satisfação". Foi utilizado o software $\mathrm{R}^{\circledR}$ e realizado o teste de Kaiser-Meyer-Olkin (KMO) para garantir se a análise fatorial era apropriada. Os resultados alcançados foram abordados ainda segundo as diretrizes de projeto e proposições de melhoria sugeridas por Morais (2015), a partir das insatisfações detectadas em entrevistas e grupos focais dos clientes finais de empreendimentos do MCMV.

\section{Análise Fatorial (AF)}

Nos empreendimentos de alto e médio padrão, utilizando da divisão do próprio questionário, as variáveis inicialmente determinadas foram:

(a) V1: área coletiva;

(b) V2: unidade habitacional - tamanho dos ambientes;

(c) V3: unidade habitacional - acabamento;

(d) V4: unidade habitacional - instalações;

(e) V5: unidade habitacional - conforto; e

(f) V6: empresa, sendo a escolha por estas 6 variáveis realizada em função da própria disposição das 35 perguntas em subgrupos, conforme Figura 2.

Quadro 1 - Informações gerais acerca das pesquisas de satisfação utilizadas

\begin{tabular}{|l|l|l|}
\hline \multicolumn{1}{|c|}{ Programa MCMV } & \multicolumn{1}{c|}{ Alto e Médio Padrão } \\
\hline $\begin{array}{l}\text { Quantidade de } \\
\text { questionários } \\
\text { aplicados }\end{array}$ & 362 & 138 \\
\hline $\begin{array}{l}\text { Características } \\
\text { dos questionários }\end{array}$ & $\begin{array}{l}\text { Escala Likert de 5 pontos (muito } \\
\text { insatisfeito a muito satisfeito). Os } \\
\text { usuários apontavam a sua satisfação } \\
\text { quanto ao item em análise. Possui 3 } \\
\text { grupos de perguntas: Localização, Área } \\
\text { coletiva, Unidade habitacional }\end{array}$ & $\begin{array}{l}\text { Escala de notas de 0 a 10. Os usuários } \\
\text { apontavam 1 nota para satisfação e 1 nota } \\
\text { para a importância daquele item para si. } \\
\text { Possui 3 grupos de perguntas: Área coletiva, } \\
\text { Unidade Habitacional, Empresa. }\end{array}$ \\
\hline $\begin{array}{l}\text { Localização dos } \\
\text { empreendimentos } \\
\text { (municípios do } \\
\text { estado do Ceará) }\end{array}$ & $\begin{array}{l}\text { Aquiraz, Cascavel, Caucaia, Fortaleza, } \\
\text { Horizonte, Itaitinga, Juazeiro do Norte, } \\
\text { Maracanaú, Maranguape, Sobral }\end{array}$ & Fortaleza \\
\hline
\end{tabular}

50 Saraiva, R. L. de P.; Barros Neto, J. de P.; Maués, L. M. F. 
Figura 1 - Modelo de análise proposto

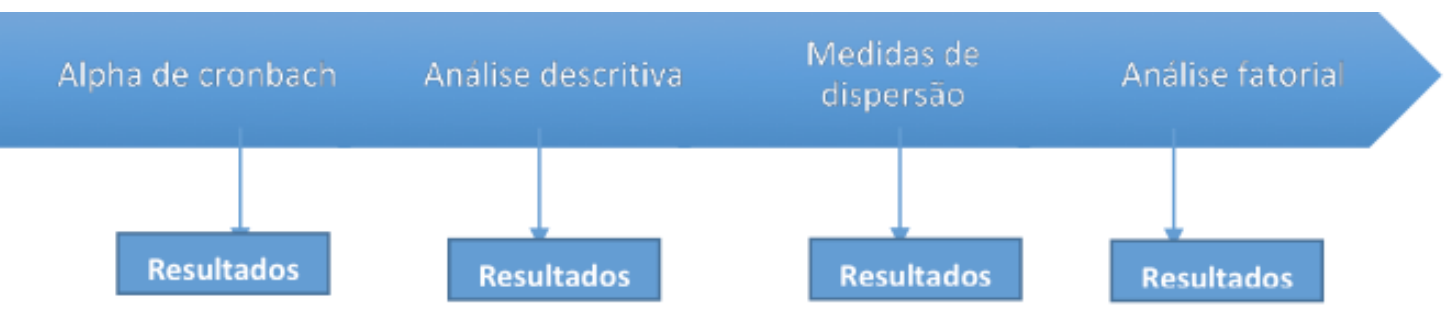

Informações para retroalimentar o processo de projeto

Figura 2 - Ilustração do questionário aplicado aos empreendimentos de alto e médio padrão

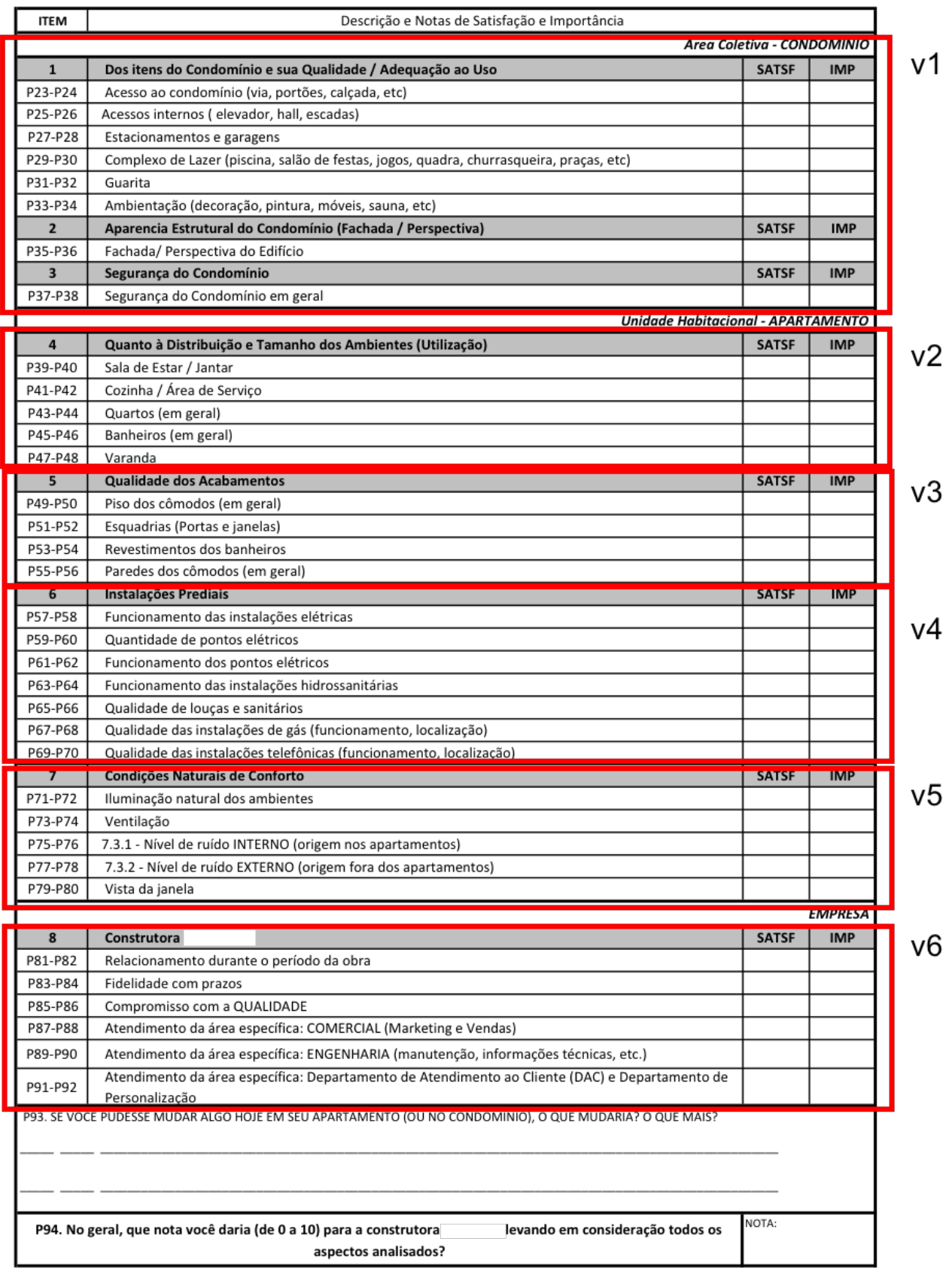


Para os resultados adivindos dos empreendimentos do Programa MCMV, a separação de variáveis se deu de forma análoga, estabelecendo as seguintes variáveis em função do agrupamento de questões no próprio questionário:
(a) V1: localização: serviços públicos;
(b) V2: localização: vizinhança;
(c) V3: área coletiva: funcionalidade;
(d) V4: área coletiva: estética;
(e) V5: unidade habitacional: funcionalidade;
(f) V6: unidade habitacional: qualidade;
(g) V7: unidade habitacional: sistemas prediais; e
(h) V8: unidade habitacional: conforto.

A Figura 3 ilustra as variáveis adotadas inicialmente para a análise fatorial.

\section{Resultados}

Esta sessão tem por objetivo a apresentação dos resultados advindos do modelo de análise, conforme apresentado na Figura 1. Após a organização e composição do banco de dados, as ferramentas e medidas foram empregadas, obtendo os resultados a seguir.

\section{Alpha de Cronbach}

A Tabela 1 ilustra os valores estimados no teste de Alpha de Cronbach realizado nas situações descritas a seguir. Foram compostos dois bancos de dados, em função da classificação dos empreendimentos (MCMV e Alto e médio padrão), e analisadas todas as respostas que compunham cada banco de dados.

Figura 3 - Ilustração do questionário aplicado aos empreendimentos do programa MCMV

\begin{tabular}{|c|c|c|c|c|c|c|}
\hline \multirow{7}{*}{ V1 } & \multicolumn{6}{|c|}{ LOCALIZACCÃO } \\
\hline & \multicolumn{2}{|r|}{ Serviços Públicos (Presença e eficiênncia dos serviços) } & $\mathbf{s}$ & \multicolumn{2}{|r|}{ Vizinhança } & \multirow[t]{2}{*}{$\mathbf{s}$} \\
\hline & $\mathrm{P} 35$ & Iluminą̧ão Pública & & $\mathrm{P} 40$ & Acesso a comércio (mercados, padarias, farmácias, etc) & \\
\hline & P36 & Abastecimento de água & & $\mathrm{P} 4 \mathrm{I}$ & Acesso a serviços (creches, escolas, postos de saúde, etc) & \\
\hline & P37 & Coleta de esgoto sanitário & & $\mathrm{P} 42$ & Acesso a lazer (parques, praças, etc) & \\
\hline & P38 & Coleta de lixo & & $\mathrm{P} 43$ & Acesso ao condominio (percurso de chegada ao empreendimento) & \\
\hline & P39 & Policiamento local & & $\mathrm{P} 44$ & Acesso a transporte püblico (para de ónibus) & \\
\hline \multirow{9}{*}{ V3 } & \multicolumn{6}{|c|}{ ÁREA COLETIVA } \\
\hline & & Funcionalidade, Qualidade e Manutençáo & $\mathbf{s}$ & & Estética, Privacidade e Segurança & $\mathbf{s}$ \\
\hline & P45 & Entrada do condominio (portões e guarita) & & P50 & Aparência das edificaçōes (blocos ou casas) & \\
\hline & P46 & Estacionamentos (vagas para carros, motos e bicicletas) & & P51 & Aparência das áreas livres (pátios, passeios, jardins, etc) & \\
\hline & $\mathrm{P} 47$ & Áreas de lazer e recreaçào (salào de festas, quadra, playground, etc) & & P52 & Fechamentos externos (muros, gradis, etc) & \\
\hline & P48 & Áreas comuns (escadas, corredores cobertos, etc) & & P53 & Cercas elétricas e dispositivos de segurança (se dado pela const.) & \\
\hline & P49 & Lixeiras & & P54 & Entrada do condominio (portôes e guarita) & \\
\hline & \multicolumn{6}{|c|}{ UNIDADE HABITACIONAL } \\
\hline & \multicolumn{2}{|r|}{ Funcionalidade (Adequação a o uso, tamanho e distribuição) } & $\mathbf{s}$ & & Qualidade (da construção e dos acabamentos) & $\mathbf{s}$ \\
\hline \multirow{7}{*}{ V5 } & P55 & Sala de estar/jantar & & P61 & Piso dos cômodos (em geral) & \\
\hline & P56 & Cozinha/Área de serviço & & P62 & Revestimentos das paredes dos banheiros & \\
\hline & P57 & Quartos & & $\mathrm{P} 63$ & Revestimentos das paredes da cozinha & \\
\hline & P58 & Banheiros & & P64 & Revestimentos das paredes de outros cômodos & \\
\hline & P59 & Varanda ou quintal (em caso de ausência de varanda inserir "00") & & P65 & Esquadrias (portas e janelas) & \\
\hline & P60 & Adequação aos móveis comprados & & P66 & Estrutura da construçào (paredes, pilares, etc) & \\
\hline & & Sistemas Prediais (instalacòes) & $\mathbf{s}$ & & Conforth (Remestar na edfificacion) & \\
\hline \multirow{13}{*}{ V7 } & P67 & Funcionamento dos pontos elétricos (tomadas e interruptores) & & P74 & Iluminação natural dos ambientes & \\
\hline & P68 & Quantidade e distribuição dos pontos elétricos (tomadas e lâmpadas) & & P75 & Ventilą̧ão natural dos ambientes & \\
\hline & P69 & Qualidade das instalą̧ø̃es de gás (funcionamento, localizaçâo) & & P76 & Nivel de ruido - INTERNO (origem nos outros apartamentos) & \\
\hline & P70 & Qualidade das instalą̧ōes telefônicas (funcionamento, localização) & & P77 & Nivel de ruido - EXTERNO (origem de for a dos apartamentos) & \\
\hline & P71 & Funcionamento dos interfones & & P78 & Privacidade do apartamento com relaçào aos vizinhos & \\
\hline & $\mathrm{P} 72$ & Funcionamento das instalaçōes hidrosanitárias em geral & & & & \\
\hline & $\mathrm{P} 73$ & Oualidade das loucas e metais hidrosanitários (torneiras,yasos. etc) & & & & \\
\hline & & & & & & \\
\hline & \multicolumn{6}{|c|}{ NOTAIS GERAIS } \\
\hline & P79 & Considerando todos os aspectos analisados, dê uma nota geral (de la & para & ALIZ & & \\
\hline & P80 & Considerando todos os aspectos analisados, dê uma nota geral (de 1 & para & $\mathrm{ACO}$ & TIVA & \\
\hline & P81 & Considerando todos os aspectos analisados, dê uma nota geral (de I a & para & DADE & ABITACIONAL & \\
\hline & P82 & Considerando todos os aspectos analisados, dê uma nota geral (de I & para & REEN & IMENTO & \\
\hline
\end{tabular}


Tabela 1 - Valores estimados de Alpha de Cronbach para cada banco de dados

\begin{tabular}{l|c|c|c}
\hline \multicolumn{1}{c|}{ Tipo Estudo } & Empreendimento & Questões & Alpha \\
\hline MCMV & Banco de Dados (Todos) & 44 & 0,8287 \\
\hline Médio e Alto Padrão & Banco de Dados (Todos) & 35 & 0,661 \\
\hline
\end{tabular}

Pode-se perceber que somente o banco de dados do MCMV teve resultado aceitável $(>0,6)$, ficando o banco de dados dos empreendimentos de médio e alto padrão ligeiramente abaixo do valor mínimo. Constata-se que a quantidade de questionários respondidos tem potencial de influenciar grandemente nestes resultados. A quantidade de empreendimentos, bem como de questionários respondidos foi:

(a) pesquisa MCMV (10 empreendimentos - 362 questionários respondidos); e

(b) pesquisa Médio e Alto Padrão (3 empreendimentos - 138 questionários respondidos).

\section{Tendência central e dispersão}

Os resultados obtidos foram resumidos nas Tabelas 2 e 3. Quanto aos resultados dos empreendimentos de médio e alto padrão, as menores notas (média e mediana) foram atribuídas às questões: 37, 53, 75 e 77. Entende-se que as notas mais baixas foram atribuídas aos aspectos que compreenderam menos satisfação aos usuários, o que explica a sua análise em maior profundidade. A questão com maior variação, foi também aquela que apresentou a menor nota, o que pode indicar que, apesar da variação, as notas baixas foram atribuídas por um número relevante de usuários. Pode-se constatar ainda que o menor valor de nota média é também o menor valor de nota mediana, o que aponta a possibilidade de exclusão de uma das duas métricas. Do mesmo modo, o coeficiente de variação $(\mathrm{CV})$, isto é, o indicativo de quanto a média de cada nota varia em relação à média geral, apresentou valores muito próximos, o que confirma essa possibilidade.

Quanto aos resultados do MCMV, as menores notas foram atribuídas às questões: 39, 42, 53, 61 e 71 e os resultados são expressos na Tabela 3. Novamente, as questões com menores notas médias apresentaram também as menores medianas, possuindo CV's consideravelmente próximos, todavia, diferente do que foi constatado anteriormente, o maior CV não foi obtido pela na pergunta com menor nota média, o que pode sugerir a existência de problemas específicos nas unidades habitacionais de alguns usuários, fator que explicaria a existência de alta variação em aspectos que não julgados uniformemente como insatisfatórios.

Diante do exposto a Tabela 5 pode ser apresentada, evidenciando as 5 maiores insatisfações de ambos os grupos de empreendimentos, isto é, as 5 questões que apresentaram menores notas, e a classificação de responsabilidade por cada questão. São propostas ainda diretrizes de correção, conforme Morais (2015).

\section{Análise fatorial}

\section{Empreendimentos de médio e alto padrão}

A Tabela 4 indica os resultados obtidos para a análise referente aos empreendimentos de médio e alto padrão, utilizando as 6 variáveis previamente estabelecidas em virtude da divisão do próprio questionário aplicado (conforme Figura 2). É importante ressaltar o alto percentual de explicação obtido pelo método quando se acumula os três primeiros fatores $(64,9 \% ; 9,54 \%$ e $8,41 \%)$, obtendo assim um total aproximado de explicação de $83 \%$.

Realizando o cálculo das cargas fatoriais e, em seguida, aplicando a técnica de rotação Varimax para melhor interpretação dos resultados, foram obtidos os resultados expressos na Tabela 5.

Como o $1^{\circ}$ fator retém a maior parte da variabilidade total dos dados e este é o fator responsável por explicar, em maior parte, as variáveis "Tamanho dos ambientes" e "Qualidade dos acabamentos", tem-se que estas variáveis são as que compreendem maior significância para a satisfação para os clientes.

Uma vez que estas variáveis são compostas por grupos de questões (conforme ilustrado na Figura 2), a análise fatorial foi refeita para ambos os grupos, separadamente, visando concluir quais as questões possuem maior capacidade de explicar a variável "satisfação" dentro de cada grupo.

A análise foi inicialmente realizada para a variável "Tamanho dos ambientes". Na Tabela 6, são apresentados os fatores e o seu percentual de explicação. Observa-se que os três primeiros fatores juntos explicam $86,56 \%$ da variabilidade total, assim sendo, optou-se por manter a análise somente com os três, o que é apresentado na Tabela 7, a partir do uso da matriz de carga rotacionada. 
Analisando a Tabela 6, pode-se concluir que o $1^{\circ}$ fator, responsável por 56,92\% da variabilidade do modelo, é responsável por explicar prioritariamente as perguntas 39 - Sala de estar/jantar; 41- Cozinha/Área de serviço; 43 - Quartos.

Pode-se concluir então que, uma vez que este fator detém a maior explicação do modelo, estes três itens são os responsáveis por impactarem, de maneira mais significativa, a satisfação dos clientes. Ou seja, há indícios para acreditar que os clientes valorizam mais o tamanho da cozinha/área de serviço, quartos e sala de estar/jantar.

O mesmo procedimento de análise foi adotado para analisar a variável "Qualidade dos acabamentos", apresentando os resultados principais na Tabela 8, que apresenta a matriz rotacionada das cargas e indica que o $1^{\circ}$ fator, detentor de mais de $65 \%$ da variabilidade total explicada, infere, principalmente, sobre 49 Piso dos cômodos; 51 - Esquadrias e 53 - Revestimento dos banheiros. Sendo estas as questões com maior capacidade de explicar a "satisfação" neste grupo de questões. Em seguida, o $2^{\circ}$ fator é responsável por explicar, principalmente a 55 - Paredes dos cômodos.

Tabela 2 - Estatística descritiva para as perguntas do questionário aplicado aos empreendimentos de alto e médio padrão

\begin{tabular}{|c|c|c|c|c|c|c|}
\hline & MÉDIA & MEDIANA & DESV PAD & VAR & CV MÉDIA & CV MEDIANA \\
\hline P23 & 8,19 & 8,00 & 1,88 & 3,54 & $23 \%$ & $24 \%$ \\
\hline P25 & 8,40 & 9,00 & 1,90 & 3,63 & $23 \%$ & $21 \%$ \\
\hline P27 & 7,89 & 8,00 & 2,35 & 5,50 & $30 \%$ & $29 \%$ \\
\hline P29 & 8,85 & 9,00 & 1,48 & 2,20 & $17 \%$ & $16 \%$ \\
\hline P31 & 7,27 & 8,00 & 2,91 & 8,45 & $40 \%$ & $36 \%$ \\
\hline P33 & 8,29 & 8,50 & 1,90 & 3,61 & $23 \%$ & $22 \%$ \\
\hline P35 & 8,67 & 9,00 & 1,59 & 2,53 & $18 \%$ & $18 \%$ \\
\hline P37 & 7,64 & 8,00 & 1,99 & 3,94 & $26 \%$ & $25 \%$ \\
\hline P39 & 8,24 & 9,00 & 2,06 & 4,24 & $25 \%$ & $23 \%$ \\
\hline P41 & 7,76 & 8,00 & 2,27 & 5,15 & $29 \%$ & $28 \%$ \\
\hline $\mathrm{P} 43$ & 8,52 & 9,00 & 1,74 & 3,01 & $20 \%$ & $19 \%$ \\
\hline $\mathrm{P} 45$ & 8,25 & 8,00 & 1,90 & 3,62 & $23 \%$ & $24 \%$ \\
\hline P47 & 9,28 & 10,00 & 1,19 & 1,41 & $13 \%$ & $12 \%$ \\
\hline P49 & 7,67 & 8,00 & 2,45 & 6,00 & $32 \%$ & $31 \%$ \\
\hline P51 & 7,79 & 8,00 & 2,21 & 4,90 & $28 \%$ & $28 \%$ \\
\hline P53 & 7,05 & 8,00 & 2,56 & 6,58 & $36 \%$ & $32 \%$ \\
\hline P55 & 7,65 & 8,00 & 2,48 & 6,13 & $32 \%$ & $31 \%$ \\
\hline P57 & 8,23 & 9,00 & 2,15 & 4,63 & $26 \%$ & $24 \%$ \\
\hline P59 & 8,25 & 8,50 & 1,88 & 3,53 & $23 \%$ & $22 \%$ \\
\hline P61 & 8,71 & 10,00 & 1,92 & 3,70 & $22 \%$ & $19 \%$ \\
\hline P63 & 8,33 & 9,00 & 2,24 & 5,01 & $27 \%$ & $25 \%$ \\
\hline P65 & 8,19 & 8,50 & 2,20 & 4,83 & $27 \%$ & $26 \%$ \\
\hline P67 & 8,82 & 10,00 & 1,93 & 3,74 & $22 \%$ & $19 \%$ \\
\hline P69 & 8,23 & 9,00 & 2,35 & 5,52 & $29 \%$ & $26 \%$ \\
\hline P71 & 9,35 & 10,00 & 1,23 & 1,51 & $13 \%$ & $12 \%$ \\
\hline P73 & 9,28 & 10,00 & 1,70 & 2,89 & $18 \%$ & $17 \%$ \\
\hline P75 & 6,78 & 7,00 & 2,91 & 8,49 & $43 \%$ & $42 \%$ \\
\hline P77 & 7,28 & 8,00 & 2,74 & 7,48 & $38 \%$ & $34 \%$ \\
\hline P79 & 8,62 & 10,00 & 2,44 & 5,93 & $28 \%$ & $24 \%$ \\
\hline P81 & 8,78 & 9,00 & 1,64 & 2,69 & $19 \%$ & $18 \%$ \\
\hline P83 & 8,51 & 9,00 & 1,88 & 3,52 & $22 \%$ & $21 \%$ \\
\hline P85 & 7,92 & 8,00 & 2,18 & 4,76 & $28 \%$ & $27 \%$ \\
\hline P87 & 8,72 & 9,00 & 1,63 & 2,66 & $19 \%$ & $18 \%$ \\
\hline P89 & 7,78 & 8,00 & 2,38 & 5,67 & $31 \%$ & $30 \%$ \\
\hline P91 & 7,89 & 8,50 & 2,36 & 5,59 & $30 \%$ & $28 \%$ \\
\hline
\end{tabular}

54 Saraiva, R. L. de P.; Barros Neto, J. de P.; Maués, L. M. F. 
Tabela 3 - Estatística descritiva para as perguntas do questionário aplicado aos empreendimentos do MCMV

\begin{tabular}{|c|c|c|c|c|c|c|}
\hline & MÉDIA & MEDIANA & DESV PAD & VAR & CV MÉDIA & CV MEDIANA \\
\hline P35 & 3,25 & 4,00 & 1,40 & 1,96 & $43 \%$ & $35 \%$ \\
\hline P36 & 3,44 & 4,00 & 1,21 & 1,46 & $35 \%$ & $30 \%$ \\
\hline P37 & 3,49 & 4,00 & 1,18 & 1,40 & $34 \%$ & $30 \%$ \\
\hline P38 & 3,80 & 4,00 & 1,05 & 1,10 & $28 \%$ & $26 \%$ \\
\hline P39 & 2,40 & 2,00 & 1,33 & 1,77 & $56 \%$ & $67 \%$ \\
\hline $\mathrm{P} 40$ & 2,71 & 2,00 & 1,32 & 1,74 & $49 \%$ & $66 \%$ \\
\hline P41 & 2,84 & 3,00 & 1,42 & 2,03 & $50 \%$ & $47 \%$ \\
\hline P42 & 1,91 & 2,00 & 1,05 & 1,10 & $55 \%$ & $52 \%$ \\
\hline P43 & 3,00 & 3,00 & 1,28 & 1,65 & $43 \%$ & $43 \%$ \\
\hline P44 & 2,77 & 2,00 & 1,45 & 2,11 & $52 \%$ & $73 \%$ \\
\hline $\mathrm{P} 45$ & 2,76 & 3,00 & 1,55 & 2,40 & $56 \%$ & $52 \%$ \\
\hline $\mathrm{P} 46$ & 3,31 & 4,00 & 1,27 & 1,62 & $38 \%$ & $32 \%$ \\
\hline $\mathrm{P} 47$ & 2,39 & 2,00 & 1,34 & 1,80 & $56 \%$ & $67 \%$ \\
\hline P48 & 3,02 & 3,50 & 1,45 & 2,09 & $48 \%$ & $41 \%$ \\
\hline P49 & 2,84 & 3,00 & 1,38 & 1,91 & $49 \%$ & $46 \%$ \\
\hline P50 & 3,96 & 4,00 & 0,96 & 0,92 & $24 \%$ & $24 \%$ \\
\hline P51 & 3,12 & 4,00 & 1,34 & 1,79 & $43 \%$ & $33 \%$ \\
\hline P52 & 3,30 & 4,00 & 1,26 & 1,59 & $38 \%$ & $31 \%$ \\
\hline P53 & 2,17 & 2,00 & 1,44 & 2,07 & $66 \%$ & $72 \%$ \\
\hline P54 & 2,73 & 3,00 & 1,56 & 2,44 & $57 \%$ & $52 \%$ \\
\hline P55 & 3,88 & 4,00 & 1,00 & 0,99 & $26 \%$ & $25 \%$ \\
\hline P56 & 3,35 & 4,00 & 1,20 & 1,45 & $36 \%$ & $30 \%$ \\
\hline P57 & 3,97 & 4,00 & 0,91 & 0,82 & $23 \%$ & $23 \%$ \\
\hline P58 & 3,95 & 4,00 & 1,01 & 1,01 & $25 \%$ & $25 \%$ \\
\hline P59 & 3,59 & 4,00 & 1,40 & 1,95 & $39 \%$ & $35 \%$ \\
\hline P60 & 3,73 & 4,00 & 1,08 & 1,18 & $29 \%$ & $27 \%$ \\
\hline P61 & 2,23 & 2,00 & 1,35 & 1,83 & $61 \%$ & $68 \%$ \\
\hline P62 & 3,64 & 4,00 & 1,11 & 1,23 & $31 \%$ & $28 \%$ \\
\hline P63 & 3,15 & 4,00 & 1,25 & 1,56 & $40 \%$ & $31 \%$ \\
\hline P64 & 3,20 & 4,00 & 1,25 & 1,56 & $39 \%$ & $31 \%$ \\
\hline P65 & 3,61 & 4,00 & 1,07 & 1,15 & $30 \%$ & $27 \%$ \\
\hline P66 & 3,77 & 4,00 & 1,02 & 1,05 & $27 \%$ & $26 \%$ \\
\hline P67 & 4,03 & 4,00 & 1,00 & 1,00 & $25 \%$ & $25 \%$ \\
\hline P68 & 4,17 & 4,00 & 0,82 & 0,67 & $20 \%$ & $20 \%$ \\
\hline P69 & 3,51 & 4,00 & 1,52 & 2,32 & $43 \%$ & $38 \%$ \\
\hline P70 & 3,05 & 4,00 & 1,71 & 2,91 & $56 \%$ & $43 \%$ \\
\hline P71 & 2,05 & 2,00 & 1,13 & 1,28 & $55 \%$ & $57 \%$ \\
\hline P72 & 3,82 & 4,00 & 0,97 & 0,94 & $25 \%$ & $24 \%$ \\
\hline P73 & 3,59 & 4,00 & 1,12 & 1,25 & $31 \%$ & $28 \%$ \\
\hline P74 & 4,16 & 4,00 & 0,75 & 0,56 & $18 \%$ & $19 \%$ \\
\hline P75 & 3,11 & 3,00 & 1,36 & 1,85 & $44 \%$ & $45 \%$ \\
\hline P76 & 2,90 & 3,00 & 1,38 & 1,90 & $48 \%$ & $46 \%$ \\
\hline P77 & 2,87 & 3,00 & 1,36 & 1,85 & $47 \%$ & $45 \%$ \\
\hline P78 & 3,30 & 4,00 & 1,35 & 1,83 & $41 \%$ & $34 \%$ \\
\hline
\end{tabular}


Tabela 4 - Variabilidade total explicada pelos fatores

\begin{tabular}{l|c|c|c|c|c|c}
\hline \multicolumn{1}{c|}{ Fator } & $\mathbf{1}$ & $\mathbf{2}$ & $\mathbf{3}$ & $\mathbf{4}$ & $\mathbf{5}$ & $\mathbf{6}$ \\
\hline Variabilidade explicada (\%) & 64,9 & 9,54 & 8,41 & 7,31 & 5,81 & 3,99 \\
Variabilidade explicada acumulada (\%) & 64,9 & 74,44 & 82,85 & 90,16 & 95,97 & 99,96 \\
\hline
\end{tabular}

Tabela 5 - Matriz de cargas rotacionada pelo método Varimax para as 6 variáveis do modelo

\begin{tabular}{l|c|c|c}
\hline \multicolumn{1}{c|}{ Variáveis } & $\mathbf{1}^{\mathbf{0}}$ fator & $\mathbf{2}^{\mathbf{0}}$ fator & $\mathbf{3}^{\mathbf{0}}$ fator \\
\hline V1 - Área Coletiva & $-0,1363$ & 0,7502 & $-0,5125$ \\
V2 - Tamanho dos ambientes (Unid. Habitacional) & $-0,8101$ & 0,2414 & $-0,2970$ \\
V3 - Qualidade dos acabamentos (Unid. Habitacional) & $-0,7745$ & 0,2996 & $-0,3559$ \\
V4 - Instalações Prediais (Unid. Habitacional) & $-0,4418$ & 0,1494 & $-0,7941$ \\
V5 - Conforto (Unid. Habitacional) & $-0,4597$ & 0,8198 & $-0,1312$ \\
V6 - Construtora (Empresa) & $-0,2783$ & 0,3771 & $-0,7356$ \\
\hline
\end{tabular}

Tabela 6 - Variabilidade total explicada pelos fatores para o grupo "Tamanho dos ambientes"

\begin{tabular}{l|c|c|c|c|c}
\hline \multicolumn{1}{c|}{ Fator } & $\mathbf{1}$ & $\mathbf{2}$ & $\mathbf{3}$ & $\mathbf{4}$ & $\mathbf{5}$ \\
\hline Variabilidade explicada (\%) & 56,92 & 19,67 & 9,97 & 7,54 & 5,9 \\
Variabilidade explicada acumulada (\%) & 56,92 & 76,59 & 86,56 & 94,1 & 100 \\
\hline
\end{tabular}

Tabela 7 - Matriz de carga rotacionada pelo método Varimax para as variáveis do grupo "Tamanho dos ambientes"

\begin{tabular}{l|c|c|c}
\hline \multicolumn{1}{c|}{ Variáveis } & $\mathbf{1}^{\mathbf{0}}$ fator & $\mathbf{2}^{\mathbf{0}}$ fator & $\mathbf{3}^{\mathbf{0}}$ fator \\
\hline P39 - Sala de estar/jantar & 0,7506 & 0,2678 & 0,3880 \\
P41 - Cozinha/Área de serviço & 0,8786 & 0,1940 & 0,0887 \\
P43 - Quartos & 0,8127 & 0,0919 & 0,2966 \\
P45 - Banheiros & 0,2762 & $-0,0247$ & 0,9481 \\
P47 - Varanda & 0,2161 & 0,9725 & $-0,0109$ \\
\hline
\end{tabular}

Tabela 8 - Matriz de carga rotacionada pelo método Varimax para as variáveis do grupo “Qualidade dos acabamentos"

\begin{tabular}{l|c|c}
\hline \multicolumn{1}{c|}{ Variáveis } & $\mathbf{1}^{\mathbf{0}}$ fator & $\mathbf{2}^{\mathbf{0}}$ fator \\
\hline P49 - Piso dos cômodos & $-0,9083$ & 0,1907 \\
P51 - Esquadrias & $-0,5935$ & 0,5044 \\
P53 - Revestimento dos banheiros & $-0,7841$ & 0,3540 \\
P55 - Paredes dos cômodos & $-0,2560$ & 0,9382 \\
\hline
\end{tabular}

Em virtude dos aspectos observados nos empreendimentos de alto e médio padrão e do programa MCMV, uma classificação das principais insatisfações é apresentada no Quadro 2, bem como diretrizes propostas para sua solução, conforme sugere Morais (2015).

Inicialmente foi realizada a análise fatorial com as 6 variáveis presentes no questionário (conforme apresentado na Figura 2). Dessa forma, foi possível concluir que as variáveis V2 (Tamanho dos ambientes) e V3 (Qualidade dos acabamentos) são as com maior possibilidade de explicar a variável "satisfação", uma vez que o $1^{\circ}$ fator retém a maior variabilidade total dos dados e é responsável, portanto, por explicar prioritariamente as variáveis em questão.

A análise fatorial foi então refeita para as variáveis V2 e V3. Em V2, foi obtido que as questões com maior potencial de explicar a satisfação dos clientes são, em ordem decrescente, 41 (Cozinha/Área de serviço); 43 (Quartos) e 39 (Sala de estar e jantar). Estes são, portanto, os aspectos mais importantes e significativos para impactar a satisfação dos clientes.

Estes resultados demonstram que, para os usuários dos empreendimentos estudados, a Cozinha e Área de serviço são ambientes tão importantes, a ponto de superar até mesmo os Quartos na possibilidade de impactar a sua satisfação.

56 Saraiva, R. L. de P.; Barros Neto, J. de P.; Maués, L. M. F. 
Quadro 2 - Classificação e diretrizes de correção para as insatisfações apresentadas

\begin{tabular}{|c|c|c|c|c|}
\hline Grupo & Questão & Descrição & Classificação & Diretriz proposta \\
\hline \multirow{5}{*}{$\begin{array}{l}\text { Alto e médio } \\
\text { padrão }\end{array}$} & 31 & Guarita & Projeto & Reestudo de implantação \\
\hline & 37 & $\begin{array}{l}\text { Segurança do } \\
\text { condomínio }\end{array}$ & Não-construtivo & - \\
\hline & 53 & $\begin{array}{l}\text { Revestimento dos } \\
\text { banheiros }\end{array}$ & Especificação & $\begin{array}{l}\text { Melhoria da qualidade de } \\
\text { materiais e componentes }\end{array}$ \\
\hline & 75 & Nível de ruído interno & Projeto & $\begin{array}{l}\text { Alteração do sistema } \\
\text { construtivo }\end{array}$ \\
\hline & 77 & Nível de ruído externo & Projeto & $\begin{array}{l}\text { Alteração do sistema } \\
\text { construtivo }\end{array}$ \\
\hline \multirow{5}{*}{ MCMV } & 39 & Policiamento local & $\begin{array}{l}\text { Atribuição do poder } \\
\text { público }\end{array}$ & $\begin{array}{l}\text { Melhoria de infraestrutura da } \\
\text { área }\end{array}$ \\
\hline & 42 & $\begin{array}{l}\text { Acesso a lazer } \\
\text { (parques, praças etc.) }\end{array}$ & $\begin{array}{l}\text { Atribuição do poder } \\
\text { público }\end{array}$ & Requalificação do entorno \\
\hline & 53 & $\begin{array}{l}\text { Cercas elétricas e } \\
\text { dispositivos de } \\
\text { segurança }\end{array}$ & Não-construtivo & - \\
\hline & 61 & Piso dos cômodos & Especificação & $\begin{array}{l}\text { Melhoria da qualidade de } \\
\text { materiais e componentes }\end{array}$ \\
\hline & 71 & $\begin{array}{l}\text { Funcionamento dos } \\
\text { interfones }\end{array}$ & Execução & $\begin{array}{l}\text { Melhoria da qualidade de } \\
\text { materiais e componentes }\end{array}$ \\
\hline
\end{tabular}

Fonte: baseado em Morais (2015).

$\mathrm{Na}$ análise de V3, foi obtido que as questões com maior potencial de explicar a satisfação dos clientes são, em ordem decrescente, 49 (Piso dos cômodos); 53 (Revestimento dos banheiros) e 51 (Esquadrias).

\section{Empreendimentos do programa MCMV}

A análise fatorial foi efetuada inicialmente utilizando as 8 variáveis previamente estabelecidas em virtude da divisão do próprio questionário aplicado (conforme Figura 3). Na Tabela 9 pode-se notar que 66,52\% é o percentual de variabilidade explicada acumulado para os três primeiros fatores, valor este significativo e que explica a manutenção da análise com apenas estes 3 fatores.

No que concerne à matriz rotacionada de cargas, apresentada pela Tabela 10, pode-se concluir que as variáveis explicadas pelo $1^{\circ}$. fator, com percentual total de explicação de $37 \%$, foram aquelas presentas no grupo "Unidade Habitacional". Assim sendo, optou-se por realizar novamente a análise fatorial, agora utilizando como variáveis apenas aquelas que compõem este grupo.

Para a análise fatorial aplicada à variável Unidade Habitacional, a variabilidade total explicada, obtida com o acúmulo de dois fatores, foi de 70,85\%, valor este considerado elevado e que corrobora com a utilização de somente estes dois fatores, conforme apresentado na Tabela 11.

Rotacionando os resultados pelo método Varimax, para os dois fatores, pode-se concluir que o $1^{\circ}$ fator, que detém maior parte da variabilidade total dos dados, explica principalmente os subgrupos Conforto e Funcionalidade. Os resultados são expressos na Tabela 12.

A análise fatorial foi então refeita para as variáveis "Funcionalidade" e "Conforto". Como resultados para a variável "Funcionalidade", obteve-se a Tabela 13 que apresenta a matriz de carga rotacionada pelos fatores e aponta que, neste grupo, as variáveis que mais impactam a satisfação do cliente são 57 - Quartos, 55 - Sala de estar/jantar e 56 - Cozinha/Área de serviço.

Quanto à variável "Conforto", verifica-se que as principais questões responsáveis pela satisfação dos clientes são 76 - Nível de ruído interno e 77 - Nível de ruído externo. Os resultados são apresentados na Tabela 14.

Inicialmente foi realizada a análise fatorial com as 8 variáveis presentes no questionário (conforme apresentado na Figura 3). Dessa forma, foi possível concluir que as variáveis componentes do grupo "Unidade Habitacional", composta pelas variáveis V5 (funcionalidade); V6 (qualidade); V7 (sistemas prediais) e V8 (conforto) são aquelas com maior possibilidade de impactar a variável "satisfação". 
Tabela 9 - Variabilidade explicada pelos fatores para o modelo de 8 variáveis

\begin{tabular}{l|c|c|c|c|c|c|c|c}
\hline \multicolumn{1}{c|}{ Fator } & $\mathbf{1}$ & $\mathbf{2}$ & $\mathbf{3}$ & $\mathbf{4}$ & $\mathbf{5}$ & $\mathbf{6}$ & $\mathbf{7}$ & $\mathbf{8}$ \\
\hline Variabilidade Explicada (\%) & 37,02 & 16,05 & 13,45 & 9,07 & 7,92 & 6,81 & 6,45 & 3,23 \\
\hline $\begin{array}{l}\text { Variabilidade Explicada } \\
\text { Acumulada (\%) }\end{array}$ & 37,02 & 53,07 & 66,52 & 75,59 & 83,51 & 90,32 & 96,77 & 100 \\
\hline
\end{tabular}

Tabela 10 - Matriz de carga rotacionada pelo método Varimax para o modelo de oito variáveis

\begin{tabular}{l|c|c|c}
\hline \multicolumn{1}{c|}{ Variáveis } & $\mathbf{1}^{\mathbf{0}}$ fator & $\mathbf{2}^{\mathbf{0}}$ fator & $\mathbf{3}^{\mathbf{0}}$ fator \\
\hline V1 - Localização (Serviço Público) & $-0,383$ & 0,248 & 0,576 \\
V2 - Localização (Vizinhança) & 0,023 & 0,006 & 0,876 \\
V3 - Funcionalidade (Área Coletiva) & $-0,147$ & 0,894 & 0,126 \\
V4 - Estética & $-0,131$ & 0,902 & 0,075 \\
V5 - Funcionalidade (Unid. Habitacional) & $-0,796$ & $-0,145$ & 0,136 \\
V6 - Qualidade & $-0,739$ & 0,251 & 0,037 \\
V7 - Sistemas Prediais & $-0,616$ & 0,378 & $-0,179$ \\
V8 - Conforto & $-0,636$ & 0,181 & 0,260 \\
\hline
\end{tabular}

Tabela 11 - Variabilidade explicada pelos fatores para as variáveis do subgrupo "Unidade Habitacional"

\begin{tabular}{l|c|c|c|c}
\hline \multicolumn{1}{c|}{ Fator } & $\mathbf{1}$ & $\mathbf{2}$ & $\mathbf{3}$ & $\mathbf{4}$ \\
\hline Variabilidade Explicada (\%) & 52,92 & 17,93 & 16,06 & 13,07 \\
Variabilidade Explicada Acumulada (\%) & 52,92 & 70,85 & 86,91 & 99,98 \\
\hline
\end{tabular}

Tabela 12 - Matriz de cargas rotacionada pelo método Varimax para as variáveis do subgrupo "Unidade Habitacional"

\begin{tabular}{l|c|c}
\hline \multicolumn{1}{c|}{ Variáveis } & $\mathbf{1}^{\mathbf{0}}$ fator & $\mathbf{2}^{\mathbf{0}}$ fator \\
\hline V5 - Funcionalidade & $-0,759$ & $-0,194$ \\
V6 - Qualidade & $-0,559$ & $-0,571$ \\
V7 - Sistemas Prediais & $-0,124$ & $-0,945$ \\
V8 - Conforto & $-0,812$ & $-0,124$ \\
\hline
\end{tabular}

Tabela 13 - Matriz de cargas rotacionada pelo método Varimax para as variáveis do subgrupo "Funcionalidade"

\begin{tabular}{l|c|c}
\hline \multicolumn{1}{c|}{ Perguntas } & $\mathbf{1}^{\mathbf{0}}$ fator & $\mathbf{2}^{\mathbf{0}}$ fator \\
\hline 55 - Sala de estar/jantar & $-0,797$ & 0,057 \\
56 - Cozinha/Área de serviço & $-0,756$ & 0,140 \\
57 - Quartos & $-0,807$ & $-0,107$ \\
58 - Banheiros & $-0,702$ & $-0,193$ \\
59 - Varanda ou quintal & $-0,048$ & $-0,942$ \\
60 - Adequação aos móveis comprados & $-0,573$ & 0,358 \\
\hline
\end{tabular}

Tabela 14 - Matriz de cargas rotacionada pelo método Varimax para as variáveis do subgrupo "Conforto"

\begin{tabular}{l|c|c}
\hline \multicolumn{1}{c|}{ Perguntas } & $\mathbf{1}^{\mathbf{0}}$ fator & $\mathbf{2}^{\mathbf{0}}$ fator \\
\hline P74 - Iluminação natural dos ambientes & 0,106 & 0,786 \\
P75 - Ventilação natural dos ambientes & 0,045 & 0,804 \\
P76 - Nível de ruído interno & 0,867 & 0,057 \\
P77 - Nível de ruído externo & 0,842 & 0,022 \\
P78 - Privacidade do apartamento em relação aos vizinhos & 0,759 & 0,073 \\
\hline
\end{tabular}


A análise fatorial foi então refeita para as variáveis do grupo "Unidade Habitacional", sendo obtido que as questões com maior potencial de explicar a satisfação dos clientes são as variáveis V5 (funcionalidade) e V8 (conforto). A análise foi então realizada novamente somente com as questões das variáveis V5 e V8, obtendo que as questões com maior possibilidade de impactar a satisfação são:

(a) V5 (quartos, sala de estar/jantar e cozinha/área de serviço); e

(b) V8 (nível de ruído interno e externo).

Os resultados obtidos na análise fatorial para as obras do programa MCMV e para os empreendimentos de médio e alto padrão foram agrupados e resumidos nas Figuras 4 e 5, sintetizando quais seriam os aspectos com maior capacidade de influenciar a satisfação dos clientes.

Figura 4 - Resumo dos resultados obtidos pela análise fatorial para as obras do programa MCMV

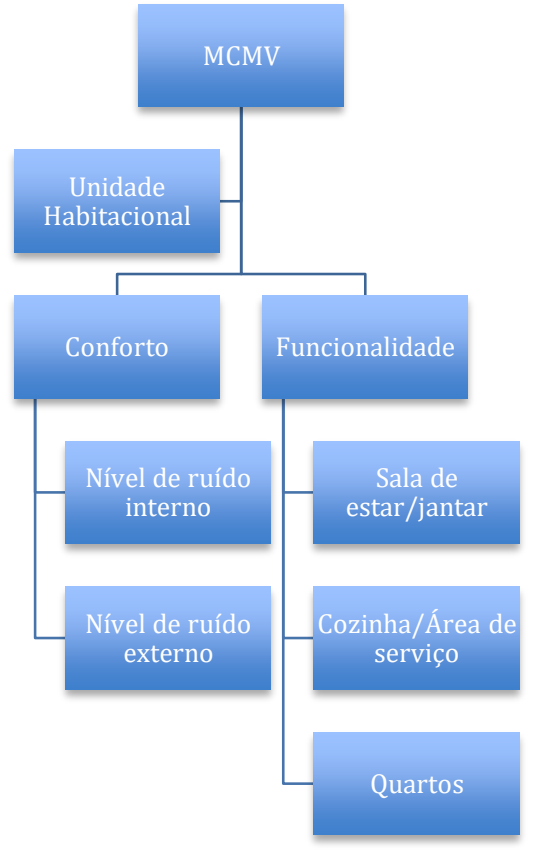

Figura 5 - Resumo dos resultados obtidos pela análise fatorial para as obras de médio e alto padrão

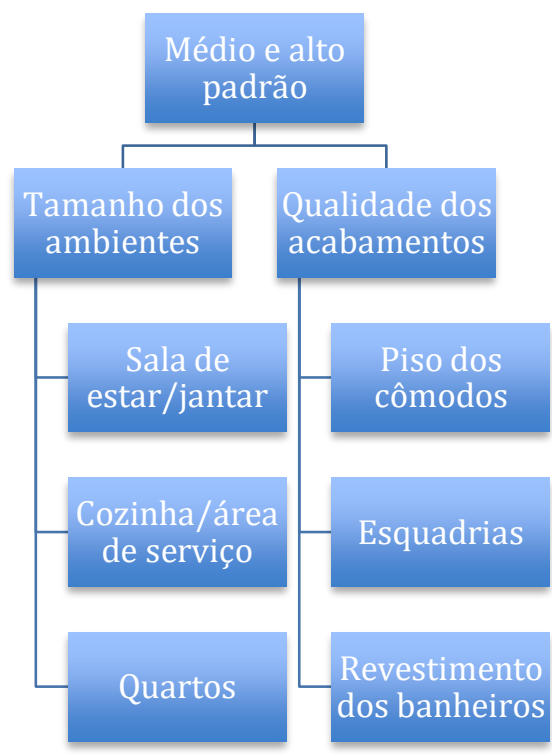


Pode-se perceber que os resultados obtidos para os empreendimentos distintos (MCVM e médio e alto padrão) possuem similaridade quanto aos ambientes sala de estar/jantar; cozinha/área de serviço e quartos. Estes resultados são importantes pois ressaltam a significância destes ambientes para a satisfação dos diferentes usuários analisados. Brito, Francisco, Echeveste (2008) identificam as áreas dos cômodos como o principal impacto relativo à unidade habitacional, identificaram sala, cozinha/área de serviço e dormitórios como os considerados mais importantes para satisfazer os clientes. Similar ao resultado do modelo aplicado por esta pesquisa.

Saramago, Villa e Portilho (2016) notaram a baixa qualidade funcional das residências ao constatar a não adequação de móveis de tamanho padrão nos espaços provenientes nos cômodos. Logsdon et al. (2016) desenvolveram uma APO através de levantamento técnico e entrevistas com moradores de um conjunto habitacional do MCMV em Cuibá/MT e constaram que, apesar da satisfação dos moradores, o empreendimento apresentou incompatibilidades com as suas necessidades, principalmente no que diz respeito às dimensões, já que alguns dos moradores chegam a ter mais de 5 filhos e quanto à flexibilidade, com problemas para inserção de móveis na residência. Estes fatores foram responsáveis por $70 \%$ das residências estudadas já terem sofrido modificações. Para Marroquim e Barbirato (2010), essas modificações quase sempre evidenciam a falta de sintonia entre o projeto arquitetônico original e as respostas às necessidades de seus usuários, evidenciando em seu estudo que maioria dos ambientes demonstrou problemas quanto aos requisitos mínimos de funcionalidade.

Quanto aos questionários empregados nas APO, pode-se perceber que a utilização da escala de Likert favoreceu a avaliação posterior realizada pelo modelo proposto neste trabalho. Desta forma, a fim de favorecer uma análise posterior, sugere-se que esta escala seja adotada nos questionários de APO e que sejam mantidas perguntas abertas aos usuários, possibilitando que manifestem insatisfações pontuais. Ao mesmo tempo pode-se evidenciar que a análise estatística tem potencial para favorecer a criação de diretrizes que embasem projetos de construção, mas deve estar aliada à análise qualitativa.

\section{Considerações finais}

Cada fase do modelo de análise proposto foi responsável por gerar importantes conclusões. Pode-se inferir que a quantidade de questionários empregados no processo de análise da satisfação dos usuários finais pode ser responsável por gerar um banco de dados de melhor ou pior qualidade, do ponto de vista numérico. Já a utilização da escala Likert de 5 pontos trouxe resultados com menor variabilidade, o que seria preferível para a aplicação deste modelo. A alta variabilidade também pode ser explicada por problemas pontuais que tenham sido enfrentados por usuários em suas unidades habitacionais, sugere-se que estas discrepâncias sejam analisadas de forma individual, a fim de não comprometer a análise geral e impactar negativamente a análise da satisfação.

A análise fatorial foi a ferramenta empregada que melhor atendeu ao objetivo do trabalho, uma vez que seus resultados indicam os atributos de projeto que são capazes de proporcionar maior satisfação para os clientes. Ao mesmo tempo vale ressaltar que as análises descritivas e de dispersão trouxeram conclusões importantes, apontando os principais itens do empreendimento que apresentaram problemas para os usuários, caracterizando-os por baixas notas. Desta forma, é importante ressaltar que o uso de todas as ferramentas utilizadas pode ser benéfico, o que não exclui nenhuma do modelo proposto.

Foram obtidos resultados similares para os empreendimentos do programa MCMV e para os empreendimentos de médio e alto padrão. Mesmo que priorizados em ordem distinta, os aspectos de projeto que apresentaram maior potencial de impactar a satisfação dos clientes são relacionados a tamanho, qualidade, funcionalidade e conforto e nos ambientes nos quais, provavelmente, os usuários passam a maior parte do tempo, como quartos, salas e cozinhas.

Utilizando as informações advindas de todo o modelo de análise proposto e comparando os resultados obtidos pode-se concluir que a qualidade é o aspecto com maior potencial de impactar a satisfação dos clientes dos empreendimentos de alto e médio e padrão, já o nível de ruído externo é o aspecto com esse potencial nos empreendimentos do programa MCMV. Essas conclusões chamam a atenção para quais aspectos os projetistas devem priorizar, a fim de obterem uma maior satisfação dos usuários finais, logo, deixa claro, que análises similares favoreceriam a criação de novos empreendimentos.

Este estudo alcançou seus objetivos ao buscar extrair de pesquisas de satisfação informações que propiciassem a hierarquização de requisitos de projeto, segundo a ótica dos clientes. A aplicação do modelo 
proposto revelou que algumas correções devem ser realizadas no questionário aplicado a fim de facilitar o uso das informações advindas do mesmo.

Propõe-se ainda que incorporadoras e construtoras empreguem este modelo de análise em seus bancos de dados próprios, a fim de nortearem o desenvolvimento de seus novos projetos e produtos, apostando em requisitos de projetos que sejam capazes de compreender uma maior satisfação dos clientes finais.

Para trabalhos futuros propõe-se que haja o aumento dos bancos de dados referentes à satisfação de clientes. Sugere-se ainda que seja realizada a aplicação do modelo de análise em outros empreendimentos, visando a generalização das conclusões obtidas e a comparação com os resultados obtidos por esta pesquisa. Sugere-se também que a futura construção de questionários já considere um posterior emprego do modelo proposto, dessa forma, evitando entraves que foram constatados. Sugere-se ainda que o emprego dos resultados de importância seja avaliado e aderido, se possível, ao modelo proposto.

\section{Referências}

ARAGÃO, D. L. L. J. de; HIROTA, E. H. Sistematização de requisitos do usuário com o uso da Casa da Qualidade do QFD na etapa de concepção de unidades habitacionais de interesse social no âmbito do Programa Minha Casa, Minha Vida. Ambiente Construído, Porto Alegre, v. 16, n. 4, p. 271-191, out./dez. 2016.

BALDAUF, J. P.; MIRON, L. L.; FORMOSO, C. T. Using BIM for modeling client requirements for lowincome housing. In: INTERNATIONAL GROUP FOR LEAN CONSTRUCTION, 2013, Fortaleza, 2013. Proceedings [...] Fortaleza, 2013.

BONATTO, F. S. Proposta de um modelo para avaliação de empreendimentos Habitacionais de Interesse Social a partir da percepção de clientes finais. Porto Alegre, 2010. Dissertação (Mestrado em Engenharia) - Universidade Federal do Rio Grande do Sul, Porto Alegre, 2010.

BRITO, J. N. S.; FORMOSO, C. T. Avaliação de Empreendimentos Habitacionais de Interesse Social com base no valor percebido pelo usuário. In: ENCONTRO NACIONAL DE TECNOLOGIA DO AMBIENTE CONSTRUÍDO, Maceió, 2014. Anais [...] Porto Alegre: ANTAC, 2014.

BRITO, J. N. S.; FORMOSO, C. T.; ROCHA, G. S. Estudo da formação de valor de usuários finais de empreendimentos habitacionais de interesse social. In: ENCONTRO NACIONAL DE TECNOLOGIA DO AMBIENTE CONSTRUÍDO, Juiz de Fora, 2012. Anais [...] Porto Alegre: ANTAC, 2012.

BRITO, J. S.; FRANCISCO, D.; ECHEVESTE, M. Gestão de requisitos em empreendimentos habitacionais de interesse social através do desdobramento da função qualidade. In: ENCONTRO NACIONAL DE TECNOLOGIA DO AMBIENTE CONSTRUÍDO, Fortaleza, 2008. Anais [...] Porto Alegre: ANTAC, 2008.

CARNEIRO, T. M. Proposta de melhoria no processo de retroalimentação dos projetos de sistemas prediais hidráulicos sanitários. Fortaleza, 2013. 169 f. Dissertação (Mestrado em Engenharia Civil: Estruturas e Construção Civil) - Centro de Tecnologia, Universidade Federal do Ceará, Fortaleza, 2013.

CORTINA, J. M. What is coefficient alpha? An examination of theory and application. Journal of Applied Psychology, v. 78, n. 1, p. 98-104, 1993.

CRONBACH, L. J. Coefficient alpha and the internal structure of tests. Psychometrika,v. 16, p. 297-334, 1951.

DELGADO-HERNANDEZ, D. J.; BAMPTON, K. E.; ASPINWALL, E. Quality function deployment in construction. Construction Management and Economics, v. 25, n. 6, p. 597-609, 2010.

DLOUHY, J. W.; HAGHSHENO, S. Evaluation of customer value by building owners in the construction process. In: INTERNATIONAL GROUP FOR LEAN CONSTRUCTION, Chennai, 2018. Proceedings [...] Chennai, 2018.

DREVLAND, F.; TILLMANN, P. A. Value for whom? In: ANNUAL CONFERENCE OF THE INTERNATIONAL: GROUP FOR LEAN CONSTRUCTION, 26., Chennai, 2018. Proceedings [...] Chennai, 2018.

FÁVERO, L. P. et al. Análise de dados: modelagem multivariada para tomada de decisões. 10 ed. Rio de Janeiro: Elsevier, 2009. 
FERNANDES, G. von der H.; FORMOSO, C. T.; TZORTZOPOULOS-FAZENDA, P. Método para verificação automatizada de requisitos em empreendimentos Habitacionais de Interesse Social. Ambiente Construído, Porto Alegre, v. 18, n. 4, p. 259-278, out./dez. 2018.

GIMÉNEZ, Z. et al. Proposal of a model for measuring value in the design process. In: ANNUAL CONFERENCE OF THE INTERNATIONAL: GROUP FOR LEAN CONSTRUCTION, 27., Dublin, 2019. Proceedings [...] Dublin, 2019.

HAIR JUNIOR, J. F. et al. Análise multivariada de dados. 5. ed. Porto Alegre: Bookman, 2005.

HATOUM, M. B. et al. Lean methods to improve end user satisfaction in higher education buildings. In: ANNUAL CONFERENCE OF THE INTERNATIONAL: GROUP FOR LEAN CONSTRUCTION, 26., Chennai, 2018. Proceedings [...] Chennai, 2018.

JYLHA, T.; JUNILLA, S. Using the Kano model to identify customer value. In: ANNUAL CONFERENCE OF THE INTERNATIONAL GROUP FOR LEAN CONSTRUCTION, San Diego, 2012. Proceedings [...] San Diego, 2012.

KAMARA, J. M.; ANUMBA, C. J.; EVBUOMWAN, N. F. O. Client requirements processing in construction: a new approach using QFD. Journal of Architectural Engineering, v. 5, n. 1, p. 8-15, mar. 1999.

KAMARA, J. M.; ANUMBA, C. J.; HOBBS, B. From briefng to client requirements processing. In: HUGHES, W. (ed.). Annual ARCOM Conference. Association of Researchers in Construction Management, 1999. v. 1, p. 317-26.

KAPLAN, R. S.; NORTON, D. P. The balanced scorecard: measures that drive performance. Harvard Business Review, Boston, v. 70, p. 71-79, jan./feb. 1992.

KÄRNA, S.; JUNNONEN, J. M. Project feedback as a tool for learning. In: ANNUAL CONFERENCE OF THE INTERNATIONAL GROUP FOR LEAN CONSTRUCTION, 13., Sydney, 2005. Proceedings [...] Sydney, 2005.

KOSKELA, L. An exploration towards a production theory and its application to construction. Helsinki, 2000. 296 f. Tese (Doutorado em Tecnologia) - Technical Research Centre of Finland - VTT, University of Technology, Helsinki, 2000.

LIMA, M. Análise de inadequações projetuais do setor serviço sob a ótica da geração de valor para o usuário em habitações de interesse social. Fortaleza, 2011. Dissertação (Mestrado em Engenharia Civil) Programa de Pós-Graduação em Engenharia Civil, Universidade Federal do Ceará, Fortaleza, 2011.

LINDAHL, G.; RYD, N. Clients' goals and the construction project management process. Facilities, v. 25, n. 3/4, p. 147-156, 2007.

LOGSDON, L. et al. O morador e a moradia: um estudo de caso no PMCMV em Cuiabá-MT. In: ENCONTRO NACIONAL DE TECNOLOGIA DO AMBIENTE CONSTRUÍDO, 16., São Paulo, 2016. Anais [...] Porto Alegre: ANTAC, 2016.

MARROQUIM, F. M. G.; BARBIRATO, G. M. Análise funcional de unidades habitacionais em MaceióAL. In: ENCONTRO NACIONAL DE TECNOLOGIA DO AMBIENTE CONSTRUÍDO, 10., Canela, 2010. Anais [...] Porto Alegre: ANTAC, 2010.

MILION, R. N.; ALVES, T. C. L.; PALIARI, J. C. Impacts of defects on customer satisfaction in residential buildings In: INTERNATIONAL GROUP FOR LEAN CONSTRUCTION, 24., Boston, 2016. Proceedings [...] Boston, 2016.

MIRON, L. I. G.; ECHEVESTE, M. E.; FORMOSO, C. T. Avaliação da satisfação e retenção como mecanismo para a gestão de requisitos do cliente. In: ENCONTRO NACIONAL DE TECNOLOGIA NO AMBIENTE CONSTRUÍDO, 12., Fortaleza, 2008. Anais [...] São Paulo: ANTAC, 2008.

MIRON, L. I. G.; FORMOSO, C. T. Gerenciamento dos requisitos do cliente em empreendimentos habitacionais. In: ENCONTRO NACIONAL DE TECNOLOGIA DO AMBIENTE CONSTRUÍDO, 9., Foz do Iguaçu, 2002. Anais [...] Foz do Iguaçu: ANTAC, 2002.

MONTEIRO, D. A. B. et al. Avaliação da percepção de valor em empreendimentos Habitacionais de Interesse Social: perspectivas de técnicos e de usuários. Ambiente Construído, Porto Alegre, v. 15, n. 4, p. 37-53, out./dez. 2015. 
MONTEIRO, D. A. B.; MIRON, L. I. G. Avaliação da retenção, satisfação e valor percebido pelos usuários de empreendimentos Habitacionais de Interesse Social. Arquisur Revista, v. 10, p. 84-107, 2016.

MONTEIRO, D. A. de B.; MIRON, L. I. G. Proposta de um método para avaliação da percepção de valor de técnicos 153 e de usuários em Habitação de Interesse Social. Ambiente Construído, Porto Alegre, v. 18, n. 1, p. 153-171, jan./mar. 2018.

MORAIS, M. V. Proposta de melhoria do projeto de habitação de interesse social a partir da visão dos clientes finais. Fortaleza, 2015. Dissertação (Mestrado em Engenharia Civil) - Programa de Pós-Graduação em Engenharia Civil, Universidade Federal do Ceará, Fortaleza, 2015.

REIS, E. Estatística multivariada. 2. ed. Lisboa: Sílabo, 2001.

SALVATIERRA-GARRIDO, J.; PASQUIRE, C.; MIRON, L. Exploring value concept through the IGLC community: Nineteen Years of Experience In: INTERNATIONAL GROUP FOR LEAN CONSTRUCTION, San Diego, 2012. Proceedings [...] San Diego, 2012.

SAMPAIO, J. C. S. et al. Modelo de retroalimentação do processo de projeto a partir de informações sobre satisfação de clientes. Ambiente Construído, Porto Alegre, v. 11, n. 4, p. 129-149, out./dez. 2011.

SAMPAIO, J. C. S. Proposição de um modelo de retroalimentação da gestão do processo de projeto a partir de medições de satisfação de clientes. Fortaleza, 2010. Dissertação (Mestrado em Engenharia Civil) - Programa de Pós-Graduação em Engenharia Civil, Universidade Federal do Ceará, Fortaleza, 2010.

SANDRONI, P. Novo dicionário de economia. São Paulo: Best Seller, 1998.

SARAMAGO, R. C. P.; VILLA, S. B.; PORTILHO, G. B. Avaliação funcional e ambiental do PMCMV: o caso do residencial jardim sucupira. In: ENCONTRO NACIONAL DE TECNOLOGIA DO AMBIENTE CONSTRUÍDO, 16., São Paulo, 2016. Anais [...] Porto Alegre: ANTAC, 2016.

STREINER, D. L. Being inconsistent about consistency: when coefficient alpha does and doesn 't matter. Journal of Personality Assessment, v. 80, p. 217-222, 2003.

TRIOLA, M. F. Introdução à estatística. 10. ed. Rio de Janeiro: LTC, 2012.

WOODRUFF, R. B. Customer value: the next source for competitive advantage. Journal of the Academy of Marketing Science, v. 25, n. 2, p. 139-153, mar. 1997.

Raísse Layane de Paula Saraiva

Programa de Pós-Graduação em Engenharia Civil | Universidade Federal do Ceará | Campus do Pici, Bloco 728 | Fortaleza - CE - Brasil | CEP 60455-900 | Tel.: (85) 3366-9607 | E-mail: raisseps@gmail.com

José de Paula Barros Neto

Programa de Pós-Graduação em Engenharia Civil | Universidade Federal do Ceará | E-mail: barrosneto@gercon.ufc.br

Luiz Maurício Furtado Maués

Programa de Pós-Graduação em Engenharia Civil | Universidade Federal do Pará | Av. Augusto Corrêa, 01, Guamá | Belém - PA - Brasil | CEP 66075-110 | Tel.: (91) 3201-8859 | E-mail: maues@ufpa.br

\section{Ambiente Construído}

Revista da Associação Nacional de Tecnologia do Ambiente Construído Av. Osvaldo Aranha, $99-3^{\circ}$ andar, Centro

Porto Alegre - RS - Brasil CEP $90035-190$

Telefone: +55 (51) 3308-4084

www.seer.ufrgs.br/ambienteconstruido www.scielo.br/ac

E-mail: ambienteconstruido@ufrgs.br 